\title{
Characterisation of cellulose pulps isolated from Miscanthus using a low-cost acidic ionic liquid
}

\author{
Wei-Chien Tu $\cdot$ Lisa Weigand $\cdot$ Michael Hummel $\cdot$ Herbert Sixta $\cdot$ \\ Agnieszka Brandt-Talbot $\cdot$ Jason P. Hallett 10
}

Received: 7 December 2018/Accepted: 19 February 2020/Published online: 12 March 2020

(C) The Author(s) 2020

\begin{abstract}
The ionoSolv pretreatment generates a cellulose pulp by extracting hemicellulose and lignin using low-cost ionic liquids. In this study, cellulose pulp was obtained from Miscanthus $\times$ giganteus using the protic ionic liquid triethylammonium hydrogen sulfate $\left[\mathrm{N}_{2220}\right]\left[\mathrm{HSO}_{4}\right]$ with $20 \%$ water as a co-solvent and characterised in detail for its material properties as a function of pretreatment severity. We measured the particle size distribution, porosity and crystallinity of the unbleached pulps and the molar weight distribution of the cellulose contained within. We report that the surface area increased and the size of the pulp particles decreased as ionoSolv processing progressed.
\end{abstract}

Electronic supplementary material The online version of this article (https://doi.org/10.1007/s10570-020-03073-1) contains supplementary material, which is available to authorized users.

W.-C. Tu · L. Weigand · A. Brandt-Talbot $(\bowtie)$.

J. P. Hallett ( $\square)$

Department of Chemical Engineering, Imperial College

London, Exhibition Road, London SW7 2AZ, UK

e-mail: agi@imperial.ac.uk

J. P. Hallett

e-mail: j.hallett@imperial.ac.uk

L. Weigand · A. Brandt-Talbot

Department of Chemistry, Imperial College London,

Wood Lane, London W12 0BZ, UK

M. Hummel · H. Sixta

Department of Bioproducts and Biosystems, Aalto

University, P.O. Box 16300, 00076 Aalto, Finland
While the native cellulose I structure was maintained, the average degree of polymerisation of the cellulose was reduced to a $\mathrm{DP}_{\mathrm{n}}$ of around 300 , showing the cellulose polymers are shortened. We correlate the pulp properties with enzymatic saccharification yields, concluding that enzymatic saccharification of the cellulose after ionoSolv pretreatment is mainly enhanced by removing hemicellulose and lignin. We also observed that overtreatment deteriorated saccharification yield and that this coincides with cellulose fibrils becoming coated with pseudolignin redeposited from the ionic liquid solution, as demonstrated by FTIR spectroscopy. Pseudolignin deposition increases the apparent lignin content, which is likely to increase chemical demand in bleaching, suggesting that both glucose release and material use benefit from a minimum lignin content. Overall, this study demonstrates that cellulose pulps isolated with ionoSolv processing are not only a promising intermediate for high-yield release of purified glucose for biorefining, but also have attractive properties for materials applications that require cellulose I fibrils. 


\section{Graphic abstract}

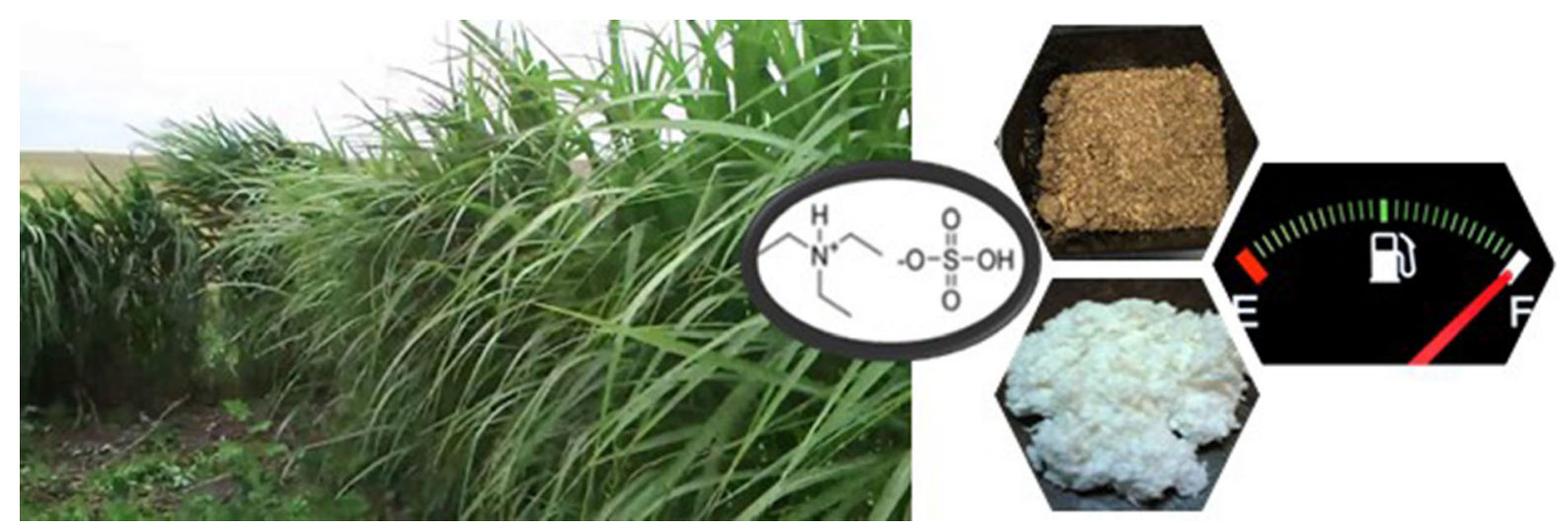

Keywords Ionic liquids - Cellulose - Crystallinity · Degree of polymerisation Pseudolignin

\section{Introduction}

Cellulose is a polymer made from glucose linked by $\beta(1 \rightarrow 4)$ glycosidic bonds. It is produced by plants, algae and microbes such as fungi and bacteria (Chen 2014). It is usually the most abundant component in the cell walls of woody (lignocellulosic) biomass. Native cellulose is bundled into microfibrils, consisting of long ordered crystalline regions that are interrupted by short amorphous regions (Habibi et al. 2010). Adjustments to properties such as hydrophilicity/hydrophobicity can be made through chemical modification of its hydroxyl groups. For example, acetylation can yield cellulose acetate which is spun into textile fibres (Edgar et al. 2001). Abundance, lowcost and desirable material properties such as high strength, biodegradability and biocompatibility have made isolated cellulose fibres and their derivatives attractive in industries ranging from paper, packaging and hygiene products to textiles, pharmaceuticals and optics (Berg and Lingqvist 2017; Edgar et al. 2001; Osong et al. 2016; Shatkin et al. 2014).

Cellulose is currently produced on an industrial scale from wood after chemical pulping using Kraft, soda or sulfite pulping (Ek et al. 2009), with the Kraft process being dominant. Global annual production of wood pulp from lignocellulose via the Kraft process reached ca. 130 million tons in 2016 (FAO 2017), accounting for two-thirds of new wood pulp production and over $90 \%$ of the chemical pulp output. Despite these processes being well established, identifying lower-cost, more environmentally friendly methods of isolating cellulose from wood is of continuing interest.

Methods to remove lignin from lignocellulosic biomass are also applied to access the sugars contained within lignocellulose for subsequent fermentation and other chemical conversions (Clark 2007), especially the glucose contained in the cellulose. Examples of pretreatment technologies that remove lignin are organosolv and alkaline pretreatment (Alvira et al. 2010; Zhao et al. 2009). Such early separation of cellulose and lignin is regarded as beneficial for fermentation yields due to absence of inhibitors, however, more cost-efficient fractionation technologies are needed (da Costa et al. 2009). This has led to the development of ionic liquid enabled lignocellulose fractionation technologies. The use of ionic liquids for lignocellulose pretreatment has attracted attention, particularly for high sugar release from a variety of lignocellulosic biomass types, making it a feedstockindependent pretreatment technology (Brandt et al. 2013). The negligible vapour pressure of many ionic liquids has the potential to simplify separations and leads to near-quantitative solvent recovery (Kuzmina 2016), which is extremely important for process economics of non-aqueous pretreatment methods. In addition, the negligible volatility of ionic liquid solvents can improve process safety and limit environmental exposure. The ability to select from a wide range of cations and anions allows for tailoring of the ionic liquid solvent to suit the application, whether catalysis and synthesis (Hallett and Welton 2011), 
electrochemical processing (Plechkova and Seddon 2008), or lignocellulose pretreatment for biorefining (Brandt et al. 2013).

Ionic liquid pretreatment can be divided into two approaches: one uses ionic liquids that dissolve or swell the whole biomass including the cellulose component, while the other approach uses ionic liquids that selectively extract lignin and hemicellulose (ionoSolv fractionation) (Brandt et al. 2013). The latter approach results in the isolation of a celluloserich pulp. Much of the research focus in the ionic liquid pretreatment field has been on the ionic liquids that swell and dissolve lignocellulose followed by an antisolvent-induced regeneration (Li et al. 2010, 2011; Sun et al. 2017). During this approach, a significant loss of order in the cellulose portion has been observed, due to an increased abundance of amorphous regions and conversion of some of the naturally occurring cellulose I into thermodynamically more stable cellulose II (Cheng et al. 2011). This makes the cellulose (and hemicellulose) highly digestible but unusable for applications where crystalline cellulose I fibrils are required. This dissolution pretreatment option commonly utilizes ionic liquids with a dialkylimidazolium cation and a chloride or acetate anion, as strong hydrogen bonding anions and poorly associating cations are required (Brandt et al. 2013). While sugar yields upon enzymatic saccharification are typically high and glucose release very fast, cellulose dissolving ionic liquids suffer from low solvent stability (Clough et al. 2013), high solvent cost (Brandt-Talbot et al. 2017), and a need for dry conditions (Doherty et al. 2010), which renders this approach technically and economically challenging for large-scale applications (Baral and Shah 2016).

IonoSolv pretreatment focuses on the extraction and dissolution of the lignin and hemicellulose components, leaving a solid, cellulose-enriched pulp after removing the IL by washing (Verdia et al. 2014). IonoSolv pretreatment can be carried out with low cost and easily synthesised ionic liquids, for example, triethylammonium hydrogen sulfate, $\left[\mathrm{N}_{2220}\right]\left[\mathrm{HSO}_{4}\right]$ (Brandt-Talbot et al. 2017). This IonoSolv ionic liquid is protic, acidic and effective in the presence of significant amounts of water. While the fractionation effect has been demonstrated in multiple conditions on a range of feedstocks (Chambon et al. 2018, 2019; Gschwend et al. 2019; Weigand et al. 2017), and the lignin has been characterised in detail (Brandt et al. 2015), the material properties of the resulting cellulose pulp remain to be determined. To fill this gap, we prepared a number of ionoSolv cellulose pulps from the energy crop Miscanthus $\times$ giganteus, a highyielding perennial grass that is a potential biorefinery feedstock, and analysed their polymer molar weight, material porosity, particle size and the cellulose crystallinity. The length of treatment time was varied to assess the impact of increasing pretreatment severity on the properties of the cellulose pulp. The material properties were correlated to the saccharification yield, providing an explanation for why there is an optimum sugar release from ionoSolv cellulose pulps.

\section{Materials and methods}

Miscanthus $\times$ giganteus was acquired from Silwood Park campus, Imperial College London. The stem biomass was air-dried, chopped, sieved to particle sizes ranging between $180-850 \mu \mathrm{m}$ and stored at room temperature in plastic bags. The moisture content of the $M$. giganteus biomass was measured using the protocol 'determination of total solids' published by the NREL (Sluiter et al. 2008).

Ionic liquid synthesis

Triethylamine ( $\geq 99 \%$ ) and $5 \mathrm{M}$ sulfuric acid were procured from Sigma Aldrich and used as received. $\left[\mathrm{N}_{2220}\right]\left[\mathrm{HSO}_{4}\right]$ was synthesised in a 1.0:1.0 acid to base ratio following the procedure outlined previously (Gschwend et al. 2016). In summary, the sulfuric acid was added dropwise into the triethylamine cooled by an ice bath and stirred until completely mixed. The water content in the ionic liquid solution was reduced using a rotary evaporator and adjusted to $20.0 \mathrm{wt} \%$ water, confirmed by Karl Fischer titration using a V20 volumetric titrator (Mettler Toledo). Titration to confirm the acid base ratio was conducted using the G20S compact titrator (Mettler Toledo). The ${ }^{1} \mathrm{H}-\mathrm{NMR}$ spectrum of the IL solution was recorded on a $400 \mathrm{MHz}$ Bruker instrument and is shown in the ESI (Figure S1).

${ }^{1} \mathrm{H}-\mathrm{NMR}$ (400 MHz, DMSO-d6, ppm): 10.2-7.5 ( $\mathrm{N}-\mathrm{H}$, broad singlet), 5.0-3.5 $\left(\mathrm{HSO}_{4}{ }^{-}\right.$and $\mathrm{DOH}$, 
broad singlet), 3.08 (q, J = 7.3 Hz, 6H), $1.17(\mathrm{t}$, $\mathrm{J}=7.3 \mathrm{~Hz}, 9 \mathrm{H})$.

\section{IonoSolv fractionation}

IonoSolv fractionation was carried out as detailed elsewhere (Gschwend et al. 2016). In brief, $1 \mathrm{~g}$ (ovendry weight) of the $M$. giganteus biomass was placed in a $15 \mathrm{~mL}$ pressure tube (Ace Glass Inc), $10 \mathrm{~g}$ of a $20 \%$ (wt/wt) $\left[\mathrm{N}_{2220}\right]\left[\mathrm{HSO}_{4}\right]$ water solution was added and the suspension mixed using a vortex mixer. The filled tubes were heated at $120^{\circ} \mathrm{C}$ for $4 \mathrm{~h}, 8 \mathrm{~h}$, and $24 \mathrm{~h}$ in a fan-assisted oven, followed by cooling to room temperature on the bench. The pretreated slurry was transferred to a $50 \mathrm{~mL}$ centrifuge tube, washed with $40 \mathrm{~mL}$ absolute ethanol and allowed to sit for $1 \mathrm{~h}$ before centrifugation for $50 \mathrm{~min}$. The liquid was decanted and the ethanol wash repeated three more times. The washed pulp was subjected to $20 \mathrm{~h}$ of Soxhlet extraction with absolute ethanol to remove residual unbound ionic liquid. The resulting pulp was air-dried for $48 \mathrm{~h}$ before being stored in a plastic bag at room temperature in the dark.

\section{Compositional analysis}

Compositional analysis was carried out according to the protocol Determination of Structural Carbohydrates and Lignin in Biomass (NREL/TP-510-42618) published by the US National Renewable Energy Laboratory, NREL (Sluiter et al. 2012). A Prominence HPLC system (Shimadzu) with RI detector was used to quantify the sugars, employing an Aminex HPX$87 \mathrm{P}$ column operated at $85^{\circ} \mathrm{C}$ with purified water at a flow rate of $0.6 \mathrm{~mL} / \mathrm{min}$.

\section{Enzymatic saccharification}

The saccharification assay was performed according to the protocol 'Low Solids Enzymatic Saccharification of Lignocellulosic Biomass' (NREL/TP-510-42629) published by the NREL (Resch et al. 2015). $20 \mu \mathrm{L}$ of cellulase enzymes (Ctec-2, Novozymes) per $100 \mathrm{mg}$ of lignocellulose or pulp were used. HPLC analysis was used to determine yields using the same conditions as detailed for compositional analysis.
X-ray diffraction (XRD) analysis

Miscanthus biomass and the isolated pulps were ground and sieved to a particle size of $53 \mu \mathrm{m}$ or less and analysed using a PANalytical Empyrean instrument, operated at $40 \mathrm{kV}$ and $40 \mathrm{~mA}$ with a $\mathrm{CuK}_{\alpha}$ radiation source. The patterns were collected in the $2 \theta$ range of $5^{\circ}-50^{\circ}$ with a step size of $0.033^{\circ}$ and a scanning rate of $70 \mathrm{~s}$ per step. The recorded XRD patterns were fitted with a standard Gaussian function using the software Origin (OriginLab). The degree of crystallinity of the lignocellulose and pulp was calculated using the Segal method. The following equation was used:

$C I=\frac{\left(I_{200}-I_{a m}\right)}{I_{200}} \cdot 100$

where $I_{200}$ is the maximum intensity at position $2 \theta=22.5^{\circ}$, assigned to the crystalline portion of cellulose in raw biomass or pulp, and $\mathrm{I}_{\mathrm{am}}$ is the minimum intensity at position $2 \theta=18^{\circ}$. The crystallite size was calculated from the diffractogram according to the Scherrer Eq. (2) using the full width half maximum value (FWHM) of the peak at position $2 \theta=22.5^{\circ}$, including the correction factor for instrument broadening.

$\tau=\frac{k \cdot \lambda}{\beta \cdot \cos \theta}$

in which $\tau=$ size of crystallites, $\mathrm{k}=$ constant shape factor of crystallites (here 0.94 ), $\lambda=$ wavelength of applied X-rays (here $0.1542 \mathrm{~nm}$ ), $\beta=$ line broadening at FWHM in radians and $\theta=$ Bragg angle in degrees.

Attenuated total reflection Fourier transform infrared (ATR FT-IR) spectroscopy

A PerkinElmer Spectrum 100 FT-IR spectrometer with a diamond ATR single reflection crystal was used to analyse the feedstock and the pretreated pulps. Initial background spectra were taken and subtracted from the sample measurement. The spectra were recorded between 500 and $4000 \mathrm{~cm}^{-1}$ with a resolution of $2 \mathrm{~cm}^{-1}$ (full spectra shown in the ESI, Figure S2). 
Particle size analysis

Approximately $1 \mathrm{~g}$ of sample was placed into deionized water and analysed using a Malvern Mastersizer 2000 with software version 5.60, which calculated the average width and length of the particles. The results were compared with microscope images of the pretreated biomass using the Nikon Eclipse Ti and NiS elements software (see Fig. S2 in ESI). Images were collated, and particles measured via ImageJ software.

Scanning electron microscopy (SEM)

A JSM 5610 LV scanning electron microscope (JEOL) was used to image untreated and pretreated samples. Samples were coated with a thin layer of gold and images were captured up with $10 \mathrm{kV}$ accelerated voltage.

Gel permeation chromatography (GPC)

Untreated $M$. giganteus and the cellulose pulps were analysed for their molar weight distribution at the Department of Forest Products Technology at Aalto University, Finland. Prior to the analysis, the samples were ground to particles smaller than 60 mesh size and delignified with sodium chlorite aqueous solution according to the method of Wise et al. (1946). The delignified samples were pre-activated by a water/ acetone/ $N, N$-dimethylacetamide (DMAc) solvent exchange sequence. The samples were then dissolved at $90 \mathrm{~g} / \mathrm{L}$ in a lithium chloride $(\mathrm{LiCl}) / \mathrm{DMAc}$ mixture at room temperature. The solutions were diluted to $9 \mathrm{~g} / \mathrm{L} \mathrm{LiCl} / \mathrm{DMAc}$ and filtered through a $0.2 \mathrm{~mm}$ syringe filter and analyzed with a Dionex Ultimate 3000 system with refractive index (RI) detection (Shodex RI-101). The $\mathrm{M}_{\mathrm{n}}$ (number average molar mass) and $\mathrm{M}_{\mathrm{w}}$ (weighted average molar mass) was calculated using Chromeleon software, and the DP determined by dividing the $\mathrm{M}_{\mathrm{n}}$ by $162 \mathrm{~g} / \mathrm{mol}$.

Measurement of surface area according

to Brunauer-Emmett-Teller (BET)

Samples were degassed with nitrogen at $80{ }^{\circ} \mathrm{C}$ overnight. Approximately $200 \mathrm{mg}$ of sample was analysed using a TriStar surface area and porosity analyser (Micromeritics). The software calculated the amount of nitrogen gas corresponding to the coverage by a multiple layers using the BET method. Pore size was determined via the adsorption average pore width using the BET model. The software package TriStar 3000 V6.07 was utilized to fit the adsorption and desorption isotherms using the Brunauer-EmmettTeller model and measurements were taken in triplicate.

\section{Results and discussion}

In order to investigate the material properties of ionoSolv cellulose pulps, milled Miscanthus was heated with $\left[\mathrm{N}_{2220}\right]\left[\mathrm{HSO}_{4}\right]$ containing $20 \%$ water at $120{ }^{\circ} \mathrm{C}$ for $4 \mathrm{~h}, 8 \mathrm{~h}$ and $24 \mathrm{~h}$, followed by washing with ethanol and air-drying to obtain the pulps. The untreated Miscanthus biomass and the resulting pulps were subjected to a raft of characterisation methods, which are discussed below.

\section{Compositional analysis}

We initially analysed the composition of the cellulose pulps to determine the cellulose recovery, approximated by glucan recovery, and to quantify the lignin and hemicellulose content in the pulps (Fig. 1).

It can be seen that ionoSolv pretreatment with $\left[\mathrm{N}_{2220}\right]\left[\mathrm{HSO}_{4}\right]$ removed and dissolved the majority of the lignin and the hemicellulose as reported previously (Brandt-Talbot et al. 2017). The majority of the glucan remained in the pulp, resulting in glucan recoveries of $84 \%, 83 \%$ and $81 \%$, for the $4 \mathrm{~h}, 8 \mathrm{~h}$ and $24 \mathrm{~h}$ fractionations, respectively. An initial drop in glucan content is well-documented for pretreatment with acidic solutions, including acidic ionic liquids, and assigned to the removal of amorphous cellulose as well as glucose contained in hemicellulose (BrandtTalbot et al. 2017; Weigand et al. 2017). The nearly unchanged glucan recovery after 24 h shows that the cellulose was stable during ionoSolv pretreatment under the conditions applied (notably a $120{ }^{\circ} \mathrm{C}$ reaction temperature). IonoSolv fractionation can be applied at higher temperatures, as the hydrogen sulfate ionic liquids have comparably high thermal stability (George et al. 2015), however, the cellulose is not stable for such a long time above $150{ }^{\circ} \mathrm{C}$ (Gschwend et al. 2018). 
Fig. 1 Composition of untreated $M$. giganteus and cellulose-rich pulps isolated ionoSolv fractionation at $120{ }^{\circ} \mathrm{C}$ using $\left[\mathrm{N}_{2220}\right]\left[\mathrm{HSO}_{4}\right]$ with $20 \%$ wt water (numerical values can be found in the ESI in Table S1) after $4 \mathrm{~h}, 8 \mathrm{~h}$ and $24 \mathrm{~h}$ of

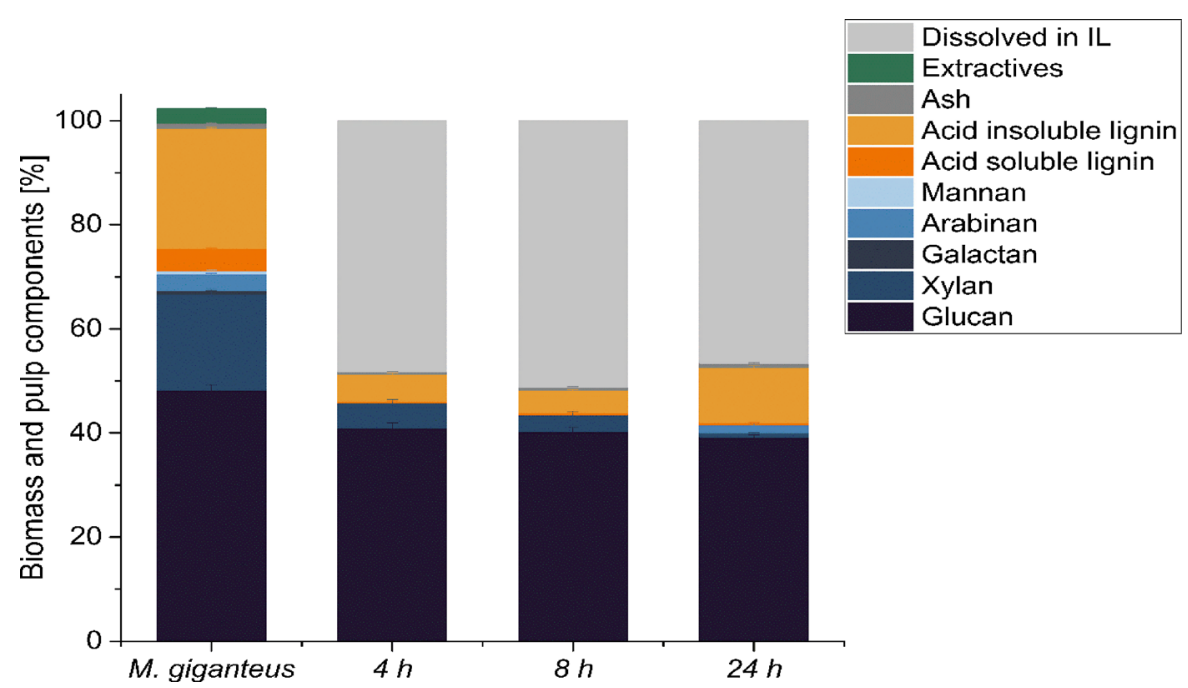

The cellulose content in the pulps was $74 \%, 82 \%$ and $79 \%$ after $4 \mathrm{~h}, 8 \mathrm{~h}$ and $24 \mathrm{~h}$ of pretreatment, respectively. The increase in cellulose content between 4 and $8 \mathrm{~h}$ was due to removal of hemicellulose and lignin, while the drop in cellulose content at $24 \mathrm{~h}$ was due to an increase in Klason lignin content, which we assign to the deposition of a lignin-like substance from the solution onto the cellulose-rich pulp. This has been observed and discussed previously for $\left[\mathrm{N}_{2220}\right]\left[\mathrm{HSO}_{4}\right]$ (Brandt-Talbot et al. 2017). Given that a low lignin content is a key target in cellulose isolation, the $24 \mathrm{~h}$ pulp was deemed to be overtreated.

We also observed a decrease in the ash content upon applying the ionic liquid. This can be attributed to the dissolution of inorganic salts into the ionic liquid solution, which has also been reported previously (Brandt-Talbot et al. 2017). The observed cellulose enrichment is comparable with commercial paper grade Kraft pulps prior to bleaching, which have cellulose contents ranging from 73 to $84 \%$, depending on the feedstock source (Borrega et al. 2017; Sjöholm et al. 2000). However, it should be noted that Kraft pulps have a higher hemicellulose content (15-27\%) and a lower lignin content (1.5-6\%) than the ionosolv pulps produced in this work.

Enzymatic saccharification yield from ionoSolv pulps

A key goal of lignocellulose pretreatment is the preparation of a deconstructed biomass for

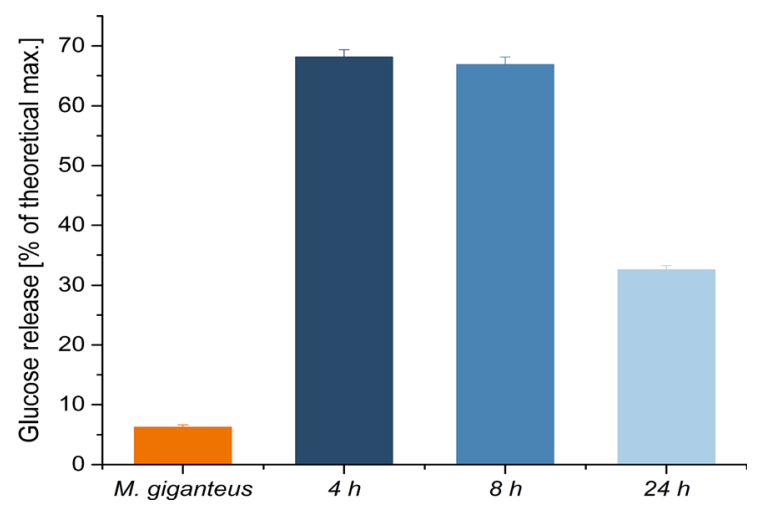

Fig. 2 Glucose release from untreated Miscanthus and ionoSolv cellulose pulps that were pretreated using the IL $\left[\mathrm{N}_{2220}\right]\left[\mathrm{HSO}_{4}\right]$ containing $20 \mathrm{wt} \%$ water, after 7 days of

fermentation of the sugar contained within. Therefore, enzymatic saccharification was performed on the cellulose-rich pulps (Fig. 2). It should be noted that previous studies conducted on the impact of the ionic liquid on saccharification yields demonstrated no discernible impact to the saccharification when the concentration of the ionic liquid in assay solution was below $1 \%$ (Karim 2017). Since the pulp loading for the saccharification assay was only $1 \%$, it would be impossible to have enough ionic liquid present to inhibit saccharification.

In this study, the enzymes released approximately $6 \%$ of the glucose from the untreated Miscanthus, while after $4 \mathrm{~h}$ and $8 \mathrm{~h}, 73 \%$ and $72 \%$ of the available glucose was released. This translates to digestibilities incubation with cellulases 
of $87 \%$ and $86 \%$ for the glucan in the ionoSolv pulps. However, the sugar release was greatly reduced for the $24 \mathrm{~h}$ pulp (35\%), with less than half of the glucan in the pulp released by the enzymes. The results show that using $\left[\mathrm{N}_{2220}\right]\left[\mathrm{HSO}_{4}\right]$ for separating cellulose from the other biopolymers greatly improved glucose release, but also that over-treatment resulted in severe reduction of access for enzyme. A link between pseudolignin deposition in the pretreated solid and decreased saccharification yield has been reported for dilute acid pretreatment (Hu et al. 2012) as well as for ionoSolv pretreatment (Brandt-Talbot et al. 2017; Weigand et al. 2017).

Analysis of chemical functionalities on the pulp surface using IR spectroscopy

ATR FT-IR spectroscopy was used to investigate changes on the surface of the biomass over the course of the pretreatment to find further evidence for pseudolignin deposition. The spectrum for untreated Miscanthus was compared to the spectra for the treated cellulose pulps. An overlay of the fingerprint regions of the IR spectra is shown in Fig. 3 (full range spectra shown in the ESI, Fig. S1). The region beyond $1800 \mathrm{~cm}^{-1}$ was not of interest, as it is dominated by
$\mathrm{OH}$ and aliphatic $\mathrm{C}-\mathrm{H}$ stretches, which are prominent in the untreated lignocellulose and in pulp alike.

The peak at $1730 \mathrm{~cm}^{-1}$ can be attributed to the stretching of carbon oxygen double bonds, as found in carboxylic acids and esters (acyl groups). The peak at $1230 \mathrm{~cm}^{-1}$ is typical for $\mathrm{C}-\mathrm{O}$ single bond stretches in esters, while alkyl-aryl C-O single bond stretches also absorb at this wave number (Liu et al. 2014; Xu et al. 2013). Esters are part of Miscanthus lignin ( $p$ coumaric acid esters) as well as Miscanthus hemicellulose (ferulic acid and acetic acid esters), while alkylaryl $\mathrm{C}-\mathrm{O}$ single bonds are present in lignin as methoxyl groups connected to the aromatic rings. It is hence unsurprising that the 1730 and $1230 \mathrm{~cm}^{-1}$ bands were strong in untreated Miscanthus. The spectrum for untreated Miscanthus also had prominent peaks at 1654,1590 , and $1505 \mathrm{~cm}^{-1}$, which are indicative of carbon-carbon bond stretches in aromatic rings, again abundantly found in lignin.

As expected, the intensity of the ester and aromatic bands was reduced in the IR spectra of the $4 \mathrm{~h}$ and $8 \mathrm{~h}$ pulps, which is consistent with the removal of lignin and hemicellulose. The decrease was more pronounced after $8 \mathrm{~h}$ of pretreatment, consistent with the compositional analysis results that show a further reduction in the lignin and hemicellulose content between $4 \mathrm{~h}$ and $8 \mathrm{~h}$.
Fig. 3 FT-IR spectra of the fingerprint region for Miscanthus and Miscanthus pulps obtained after ionoSolv fractionation at $4 \mathrm{~h}, 8 \mathrm{~h}$, and $24 \mathrm{~h}$. Solid lines: lignin aromatic stretches, dashed lines: pseudolignin aromatic stretches

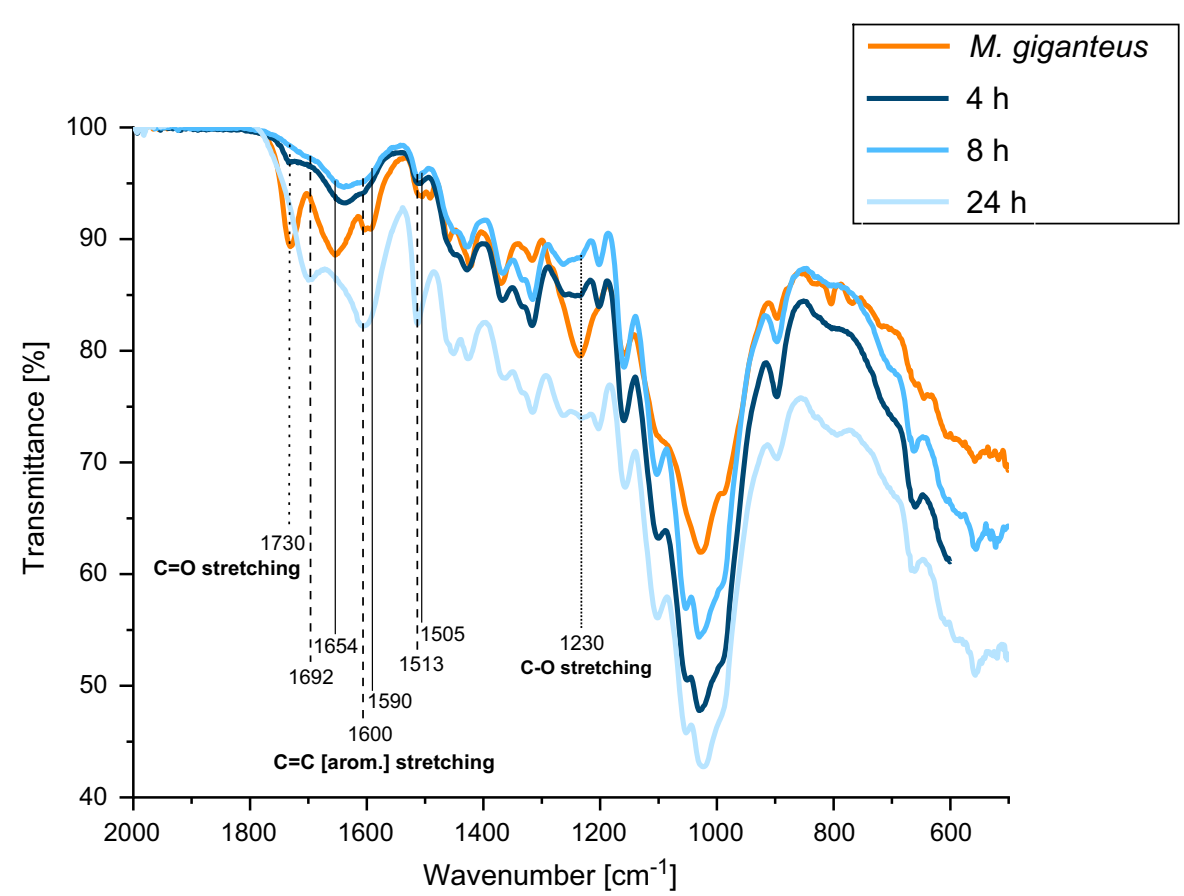


Interestingly, for the over-treated $24 \mathrm{~h}$ pulp, new peaks appeared in the acyl and aromatic regions (1692, 1600 , and $1513 \mathrm{~cm}^{-1}$ ). Others have reported similar signals for pseudolignin formed from hollocellulose (cellulose and hemicellulose) in hot dilute aqueous acid (Hu et al. 2012). The chemical structure of pseudolignin is not entirely known, but it is suspected that it contains benzenetriol structures derived from pentose and methyl chromone motifs derived from hexoses (Shinde et al. 2018). Interestingly, the peak positions found by $\mathrm{Hu}$ et al. are not identical to the positions found here. This suggests that the presence of IL and dissolved lignin during ionoSolv processing may affect the chemical structure of the deposited pseudolignin. Further studies on the chemical structure of ionoSolv generated pseudolignin are underway and will be published shortly.

Analysis of cellulose pulp crystallinity by X-ray diffraction

For lignocellulose dissolving ionic liquids, such as [Emim][OAc], a correlation between changes in cellulose crystallinity and enhancement of enzymatic glucose release from the pretreated biomass has been established by numerous studies, and it is viewed as key to their pretreatment performance (Doherty et al. 2010; Li et al. 2010). It is typically found that the more the cellulose I structure is disturbed, the more digestible the cellulose becomes. A correlation with reduced lignin content was also observed, although delignification is typically limited under cellulose dissolving conditions, usually to no more than $50 \%$. Conversely, enzymatic saccharification yields correlate very strongly with reduced lignin content for ionoSolv pretreatment (Gschwend et al. 2018), and more than $90 \%$ of lignin can be extracted with ionosolv pretreatment (Brandt et al. 2011). However, little is known about the impact of the ligninextracting ionic liquids on the crystallinity of the cellulose. Hence, we subjected the pulps to X-ray diffraction measurements to understand whether changes in the ordering of cellulose occur during ionoSolv pretreatment and to determine the apparent cellulose crystallite size.

Figure 4 shows the X-ray diffractograms of untreated Miscanthus $\times$ giganteus and the pulps recovered after ionoSolv pretreatment. The diffractograms for both untreated and pretreated samples are

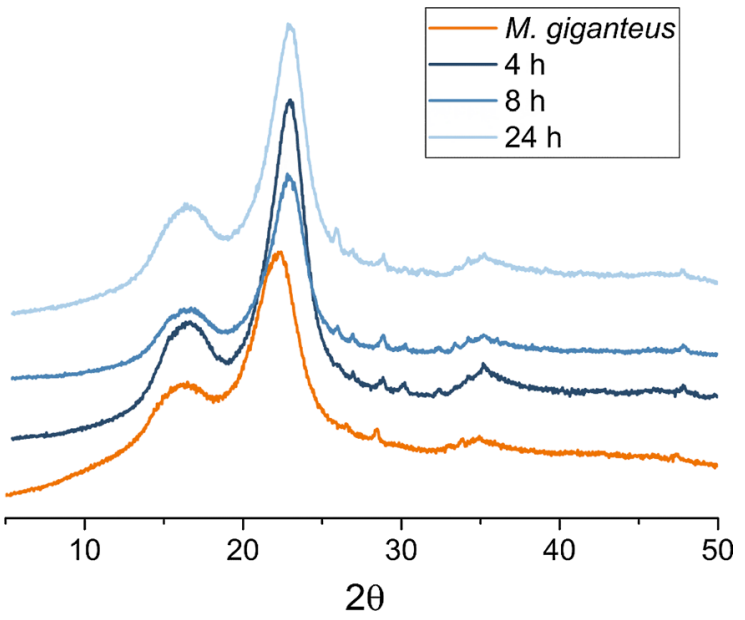

Fig. 4 XRD diffractograms of untreated Miscanthus and cellulose pulp isolated after $4 \mathrm{~h}, 8 \mathrm{~h}$ and $24 \mathrm{~h}$ of pretreatment at $120{ }^{\circ} \mathrm{C}$ with a $\left[\mathrm{N}_{2220}\right]\left[\mathrm{HSO}_{4}\right]+20 \mathrm{wt} \%$ solution, showing that the crystal structure of the cellulose is not changed during pretreatment with acidic ionic liquid water mixtures

typical for the natural cellulose I polymorph, with 3 major peaks visible at $15^{\circ}-16^{\circ}, 22^{\circ}$ and $35^{\circ} 2 \theta$. These correspond, respectively, to the [110] $+\left[\begin{array}{lll}1 & \overline{1} & 0\end{array}\right],[200]$ and [004] crystallographic planes of cellulose I (Park et al. 2010). The most intense reflection at $22^{\circ} 2 \theta$ corresponds to the [200] plane of cellulose.

There are also minor reflections in the diffractograms and we want to discuss them briefly. Given their shapes and positions, they are unlikely to originate from cellulose, but instead signify the presence of other organic or inorganic crystalline structures. In untreated Miscanthus, we found minor reflections at $26.5^{\circ}, 28.4^{\circ}, 33.0^{\circ}, 33.8^{\circ}$ and $47.4^{\circ} 2 \theta$. Similar additional reflections have been observed by others in Miscanthus or related biomass such as sugarcane bagasse (Kumar et al. 2014; Tsaneva et al. 2014), although these peaks were not discussed. We note that these reflections were preserved in the pulps, suggesting that the substance(s) causing them were not removed by the ionic liquid or the subsequent washing steps. In addition, new reflections at $25.6^{\circ}, 29.9^{\circ}$ and $32.0^{\circ} 2 \theta$ were observed in the pulps. We note that the intensity of the reflection at $25.6^{\circ}$ increased with pretreatment time and was particularly strong in the $24 \mathrm{~h}$ sample, so this could be associated with pseudolignin deposition. We speculate that the generation of micrographitic structures, which exhibit a reflection around $25^{\circ} 2 \theta$, may be responsible for this 
peak. Graphitic structures have been observed when biomass sugars are subjected to high acidity for longer periods of time (Hargreaves and Cooper 2016). This could also play a role here, as the ionic liquid employed is acidic and contains dissolved and hydrolysed hemicellulose. The reflections at $29.9^{\circ}$ and $32.0^{\circ} 2 \theta$ were observed in the $4 \mathrm{~h}$ and $8 \mathrm{~h}$ pulps but not in the overtreated $24 \mathrm{~h}$ pulp, and it is currently unclear which compound they belong to. These minor reflections need further investigation, supported by identifying and quantifying metals in Miscanthus and in the pulps, as tracking of non-process elements and fractions is important for industrial implemention, and work is underway to understand these.

For the cellulose reflections, the crystallinity index (CI) was calculated using the Segal method, which can be used to rapidly estimate the relative crystallinity of cellulose in a variety of samples, and the results are tabulated in Table 1 (French and Santiago Cintrón 2013; Segal et al. 1959). It was found that the Segal CI increased from $53.6 \%$ for untreated Miscanthus $\times$ giganteus to $73.0 \%$ for the pulp recovered after $4 \mathrm{~h}$. This suggests that there was a notable increase in the cellulose I content of the pulp. The increased CI is ascribed to the removal of lignin and hemicellulose, as well as removal of amorphous (less ordered/crystalline) cellulose domains of the cellulose fibrils, which is typical for acidic pretreatment of cellulosic substrates. Another indicator for significantly more crystalline cellulose is a slight shift of the major [200] reflection from $22.4^{\circ} 2 \theta$ for untreated biomass to $22.6^{\circ}$ $2 \theta$ for ionoSolv pulps. These results show that ionoSolv pretreatment has a fundamentally different effect on cellulose compared to pretreatment with wood dissolving ionic liquids, where the diffractograms show that the recovered cellulose is less ordered and that a minor component of the cellulose

Table 1 Crystallinity Index (CI) and crystallite size of untreated Miscanthus giganteus (entry 1) and ionoSolv pretreated pulp (entry $2-4$ )

\begin{tabular}{lccl}
\hline Entry & Pretreatment time (h) & CI (\%) & Crystallite size $(\mathrm{nm})$ \\
\hline 1 & 0 & 53.6 & 3.04 \\
2 & 4 & 73.0 & 3.82 \\
3 & 8 & 70.9 & 3.90 \\
4 & 24 & 69.4 & 3.88 \\
\hline
\end{tabular}

forms a different allomorph (cellulose II) (Socha et al. 2013). This is in agreement with various reports that found that ionic liquids with sulfate based anions cannot dissolve wood (Doherty et al. 2010) and cellulose (Mao et al. 2015), which can be ascribed to their moderate hydrogen bond basicity. Indeed, the Kamlet-Taft $\beta$ parameter, which indicates strength of hydrogen bond basicity, has been determined as 0.67 for pure $\left[\mathrm{C}_{4} \mathrm{C}_{1} \mathrm{im}\right]\left[\mathrm{HSO}_{4}\right]$ (Brandt et al. 2011) compared to 1.20 for the cellulose dissolving $\left[\mathrm{C}_{4} \mathrm{C}_{1 \text { - }}\right.$ $\mathrm{im}][\mathrm{OAc}]$ and 0.83 for the cellulose dissolving $\left[\mathrm{C}_{4} \mathrm{C}_{1} \mathrm{im}\right] \mathrm{Cl}$ (Brandt et al. 2010).

The Segal crystallinity index found here was similar to CIs obtained for organosolv pulps (Zhang et al. 2010) but was higher than the CIs for dilute acid pretreated biomass. When Miscanthus $\times$ giganteus was pretreated with aqueous dilute acid, which only removes the hemicellulose fraction, it was found that the CI increased only moderately, from 29.6 to $35.2 \%$ for Miscanthus pith and from 46.7 to $50.6 \%$ for Miscanthus rind ( $\mathrm{Ji}$ et al. 2016). The lower crystallinity index observed for dilute acid pretreated Miscanthus pulp can be attributed to the presence of lignin, as the majority of the lignin is not removed by aqueous acid.

Although the CI was higher for all ionoSolv pretreated pulps generated in this study compared to the reported CIs for dilute acids pulps, we did observe a slight decrease from $73.0 \%$ for $4 \mathrm{~h}$ to $70.9 \%$ and $69.4 \%$ for the pulps pretreated for $8 \mathrm{~h}$ and $24 \mathrm{~h}$. We hypothesise that the reduction in CI could be due to a limited amount of cellulose decrystallization. As mentioned, the hydrogen bond basicity of hydrogen sulfate ionic liquids is too low for enabling cellulose decrystallisation, however, they could have the ability to cause a minor amount of disordering in cellulose fibrils over time, potentially limited to the surface of the fibrils. Deposition of condensed lignin or pseudolignin on the pulp could also contribute to the small observed decrease in the crystallinity index between 8 and $24 \mathrm{~h}$ of pretreatment.

We also observed that the width of the $22.6^{\circ} 2 \theta$ diffraction peak decreased after ionoSolv pretreatment. The full width at half maximum (FWHM) of the diffraction pattern at $22^{\circ} 2 \theta$ can be used to calculate an apparent crystallite size, which is also shown in Table 1 (Scherrer 1912). Our data suggest that the cellulose crystallite size increased from $3.04 \mathrm{~nm}$ for raw biomass to $3.82 \mathrm{~nm}$ and $3.90 \mathrm{~nm}$ for pulps 
isolated after $4 \mathrm{~h}$ and $8 \mathrm{~h}$ pretreatment, respectively. This apparent increase in cellulose crystallite size was likely caused by the removal of hemicellulose and lignin followed by drying, leading to coalescence and clustering of cellulose fibres. A similar increase in cellulose crystallite size was described by Sun et al. (2014) for hardwood poplar after dilute acid pretreatment. The crystallite size did not increase beyond the optimum delignification time point.

The high crystallinity of the cellulose in ionoSolv pulps is likely the reason for the slower enzyme hydrolysis rates observed for ionoSolv pretreatment compared to regenerated biomass obtained after treatment with cellulose dissolving ionic liquids, such as [emim][OAc] or [bmim] Cl (Dadi et al. 2006; Li et al. 2010). Fast hydrolysis rates have also been reported for other crystallinity reducing treatments of cellulose such as swelling in phosphoric acid and clear link between cellulose crystallinity and hydrolysis rate has been demonstrated (Zhang et al. 2006).

Effect of ionoSolv pretreatment on pulp surface area and porosity

Monitoring the morphology of unbleached cellulose pulp is important for subsequent applications. A larger surface area allows not only better access for enzymes (Seidel et al. 2017) but can also affect mechanical strength of the refined cellulose materials (Horn 1978). The effect of ionoSolv pretreatment on the porosity and surface area of the pulps was hence monitored using BET surface area analysis and results are shown in Fig. 5.

The figure shows that the $\left[\mathrm{N}_{2220}\right]\left[\mathrm{HSO}_{4}\right]$ fractionation resulted in material with increased surface area, up to eight-fold compared with the untreated ground Miscanthus. The untreated Miscanthus had an average surface area of $0.49 \mathrm{~m}^{2} / \mathrm{g}$, while the surface area of the pulps after air-drying was $3.54(4 \mathrm{~h}), 2.95(8 \mathrm{~h})$ and $4.34(24 \mathrm{~h}) \mathrm{m}^{2} / \mathrm{g}$. It is unclear, why the surface area for the $8 \mathrm{~h}$ cellulose pulp was smaller than the surface area for the less and more treated $4 \mathrm{~h}$ and $24 \mathrm{~h}$ pulps. A surface area below $1 \mathrm{~m}^{2} / \mathrm{g}$ for untreated biomass was expected, however, the surface area of the pulp material was smaller than reported for unbleached pulps by others. Chen et al. measured a surface area of $16.5 \mathrm{~m}^{2} / \mathrm{g}$ for never-dried unbleached wheat straw pulp, which reduced to $12.8 \mathrm{~m}^{2} / \mathrm{g}$ upon applying drying (Chen et al. 2010). The differences in surface area observed here and for the wheat straw could be due to the different feedstocks and pulping conditions. It is expected that more exposed cellulose fibres result in a larger the measured surface area, and that completing lignin removal with a bleaching step would increase the surface area further.

Connected with the increase in surface area, there was a decrease in average pore size when compared with the untreated Miscanthus, however this was not as pronounced as the increase in surface area. The average pore size for untreated Miscanthus was $8.5 \mathrm{~nm}$, compared to $6.9 \mathrm{~nm}, 7.7 \mathrm{~nm}$ and $7.5 \mathrm{~nm}$ for the $4 \mathrm{~h}, 8 \mathrm{~h}$ and $24 \mathrm{~h}$ pulps. The observed average pore
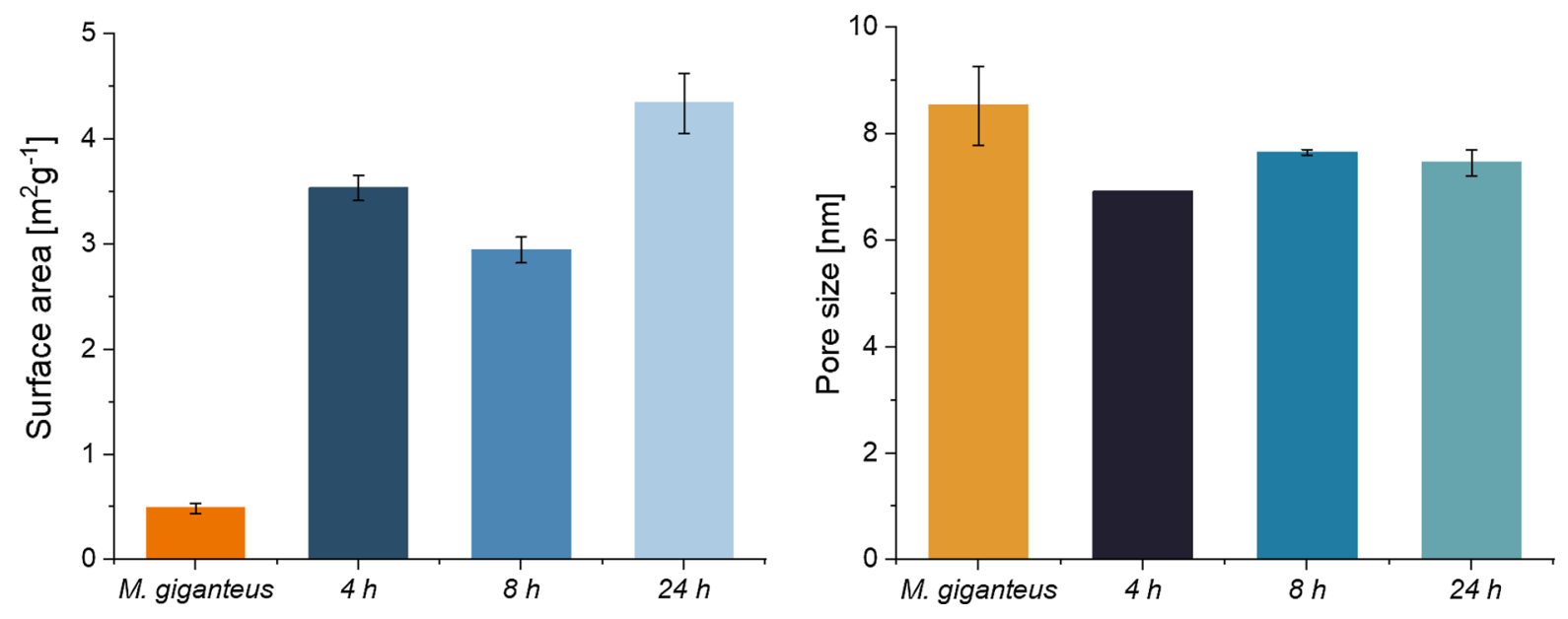

Fig. 5 BET surface area (left) and average adsorption pore width (right) of untreated $M$. X gigantheus biomass compared to ionoSolv cellulose-rich pulps pretreated with $\left[\mathrm{N}_{2220}\right]\left[\mathrm{HSO}_{4}\right]$ containing $20 \mathrm{wt} \%$ water at $120{ }^{\circ} \mathrm{C}$ 
size agrees with pore size ranges found by others for unbleached cellulose-rich pulps. Chen et al. found an average pore size of $6.3 \mathrm{~nm}$ for unbleached wheat straw pulp upon BET analysis (Chen et al. 2010) and $\mathrm{Li}$ and Henriksson found pore sizes of 9-11 nm for unbleached wood pulps when using an NMR analysis technique (Li et al. 1993).

Pulp morphology was also assessed by SEM and the images are shown in Fig. 6. Significant changes were observed over the course of the pretreatment. Untreated Miscanthus exhibited a relatively intact particle surface, which tallies well with the small surface area measured by BET analysis and micrographs shown in the ESI (Figure S3), while after 4 to $8 \mathrm{~h}$ of pretreatment, peeling and deeper fissures were observed. By $24 \mathrm{~h}$, the particles were significantly disrupted, showing that the pretreatment weakens the cell wall scaffold. We note that the fractionation also exposed micropores that are not visible in the dried untreated biomass; these pits are likely the plasmodesmata connecting plant cell wall lumens (Davison et al. 2013) (Fig. 7).

\section{Particle size}

Particle size is another measure of pulp morphology. Milling of Miscanthus results in fibrous (non-isotropic) particles, which is reflected in the particle size

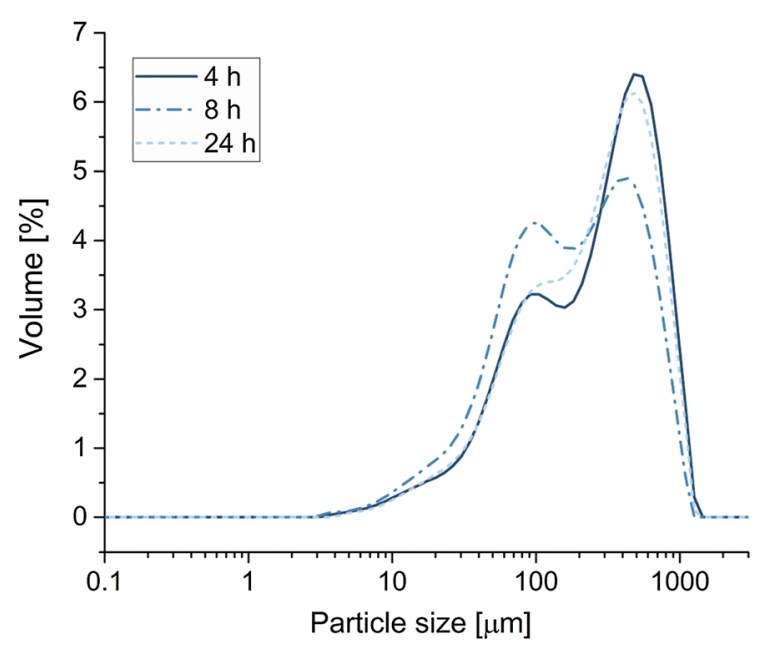

Fig. 7 Particle size of Miscanthus pulps isolated after 4 h, 8 h, and $24 \mathrm{~h}$ of pretreatment with $\left[\mathrm{N}_{2220}\right]\left[\mathrm{HSO}_{4}\right]$ containing $20 \mathrm{wt} \%$ water at $120{ }^{\circ} \mathrm{C}$

data as separate length and width size distributions (Table 2, entry 1). The untreated Miscanthus, which had been milled and sieved to a particle size of $180-850 \mu \mathrm{m}$, had an average particle width of $302 \mu \mathrm{m}$ and an average length of $1388 \mu \mathrm{m}$, showing that the average particle length is more than four times larger than the width.

After $4 \mathrm{~h}$ of pretreatment, there was a significant decrease in the average length of the particles; however, the average particle width had not changed
Fig. 6 SEM images of Miscanthus before pretreatment (a), and pulps obtained after $4 \mathrm{~h}(\mathbf{b}), 8 \mathrm{~h}$ (c) and $24 \mathrm{~h}$ (d) $\left[\mathrm{N}_{2220}\right]\left[\mathrm{HSO}_{4}\right]$ containing $20 \mathrm{wt} \%$ water at $120{ }^{\circ} \mathrm{C}$, showing an increase in particle disruption and layers peeling off the surface
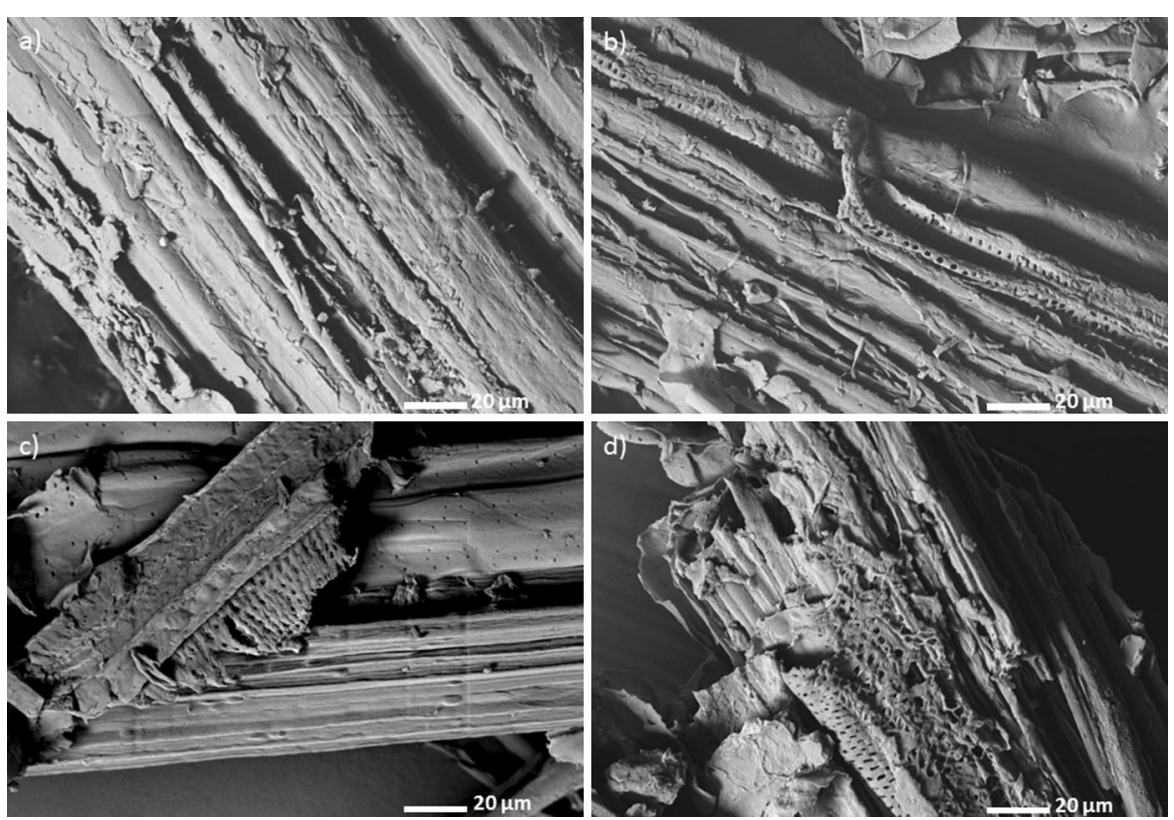
Table 2 Greatest percentage volume width and length for untreated ground Miscanthus and for pulp isolated after pretreatment pretreatment with $\left[\mathrm{N}_{2220}\right]\left[\mathrm{HSO}_{4}\right]$ containing $20 \%$ wt water at $120{ }^{\circ} \mathrm{C}$

\begin{tabular}{llc}
\hline Treatment & Average width $(\mu \mathrm{m})$ & Average Length $(\mu \mathrm{m})$ \\
\hline Untreated Miscanthus & 302 & 1388 \\
$4 \mathrm{~h}$ & 310 & 803 \\
$8 \mathrm{~h}$ & 193 & 665 \\
$24 \mathrm{~h}$ & 286 & 769 \\
\hline
\end{tabular}

substantially $(310 \mu \mathrm{m})$. A significant decrease in the width and length of the particles occurred after elongating pretreatment, with a width of $193 \mu \mathrm{m}$ and a length of $665 \mu \mathrm{m}$ after $8 \mathrm{~h}$ of pretreatment. This shows that the lignocellulose composite is disrupted during ionoSolv pretreatment, and that particle length is particularly affected. Interestingly, there was a slight increase in the average particle width and length for the $24 \mathrm{~h}$ pulp, from $193 \mu \mathrm{m}$ to $286 \mu \mathrm{m}$ and from $665 \mu \mathrm{m}$ to $769 \mu \mathrm{m}$, respectively. This suggests that the deposition of pseudolignin onto the surface of the pulp resulted in bigger particles due to coating. It may even have joined together some particles that were previously separate.

Polysaccharide molar weight and degree of polymerisation

The pretreatment method can have a substantial impact on the average molar weight $\left(M_{n}\right.$ and $\left.M_{w}\right)$ and the degree of polymerization (DP) of the cellulose in cellulose pulps. While cellulose is the dominant polysaccharide in pulps, any hemicellulose present also influences the measured molar weight and DP. The $M_{n}$ and $M_{w}$ are determined by size exclusion chromatography (SEC) after dissolving a delignified pulp in a suitable solvent system, while the DP can also be determined by measuring the intrinsic viscosity of such a solution (DPv). The number average DP for the polysaccharides is typically 300-700 for direct fibre and dissolving applications, and 150-300 for microcrystalline cellulose or cellulose nanocrystals (Kontturi et al. 2016; Palme et al. 2016).

In this study, we determined the average molar weights and corresponding DPs of the holocellulose in the ionoSolv pulps using size exclusion chromatography (chromatograms and numerical values are shown in the ESI, Fig. S4-S7 and Table S2). We saw that both
$M_{w}$ and $M_{n}$ decreased as a result of ionoSolv pretreatment (Fig. 8, left), with the $\mathrm{M}_{\mathrm{w}}$ decreasing more sharply. The number and weight average molar weights for Miscanthus holocellulose were $68 / 646 \mathrm{kDa} / \mathrm{mol} \quad\left(\mathrm{M}_{\mathrm{n}} / \mathrm{M}_{\mathrm{w}}\right)$. This decreased to $50 / 467 \mathrm{kDa} / \mathrm{mol}$ and $50 / 386 \mathrm{kDa} / \mathrm{mol}$ for the $4 \mathrm{~h}$ and $8 \mathrm{~h}$ ionoSolv pulps, falling further to $42 / 220 \mathrm{kDa} / \mathrm{mol}$ for the overtreated $24 \mathrm{~h}$ pulp. The decreasing molar weight averages demonstrate that ionoSolv pretreatment reduces the chain length of cellulose. This was not unexpected, given that the ionic liquid solution is an acidic solvent (De Gregorio et al. 2016). We note that the molar weights determined here are in the range found for commercial wood pulps. Palme et al. measured the following $M_{n} / M_{w}$ values using SEC: $57.2 / 331 \mathrm{kDa}$ (bleached softwood paper grade Kraft pulp), 58.9/182 kDa (pre-hydrolysis eucalyptus Kraft pulp) and 40.4/283 kDa (Scandinavian softwood sulfite pulp) (Palme et al. 2016).

As a result of the more strongly decreasing $\mathrm{M}_{\mathrm{w}}$, the pulp polydispersity index $\left(\mathrm{PDI}=\mathrm{M}_{\mathrm{w}} / \mathrm{M}_{\mathrm{n}}\right)$ decreased steadily from 9.4 to 7.8 and 5.3 for the $4 \mathrm{~h}, 8 \mathrm{~h}$ and $24 \mathrm{~h}$ pulps, respectively. The reduction in PDI is ascribed to preferential hydrolysis of longer cellulose chains and the more complete hemicellulose removal. To illustrate this, Fig. 8 (right) shows size fractions of DPs for the investigated samples. For the untreated Miscanthus, a significant proportion (42 mol\%) of the holocellulose had a high DP above 2000. This decreased to $33 \%, 29 \%$ and $18 \%$ when ionoSolv fractionation was applied for $4 \mathrm{~h}, 8 \mathrm{~h}$, and $24 \mathrm{~h}$, respectively, highlighting that cleavage of long cellulose chains is a leading cause of the decreasing $\mathrm{M}_{\mathrm{w}}$ and PDI.

We also calculated the number average and weight average DPs and found that they were $419 / 3987$ for untreated Miscanthus. The DP decreased to 306/2880 for the cellulose pulp isolated after $4 \mathrm{~h}$, to $306 / 2378$ 


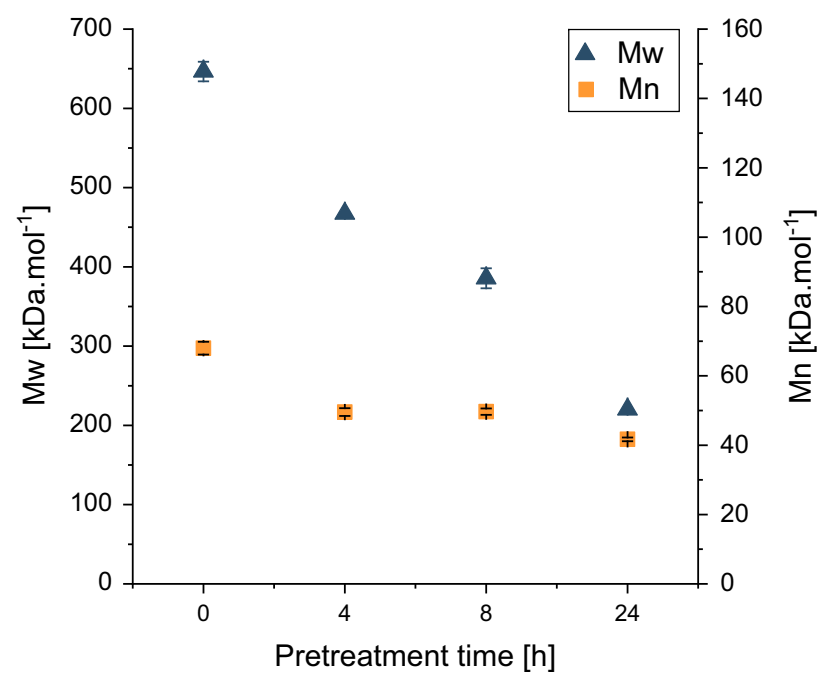

Fig. 8 The number average molar weight $\left(M_{n}\right)$ and weight average molar weight $\left(\mathrm{M}_{\mathrm{w}}\right)$ of the holocellulose in untreated Miscanthus and in the $4 \mathrm{~h}, 8 \mathrm{~h}$, and $24 \mathrm{~h}$ pulps isolated with ionoSolv pretreatment using $\left[\mathrm{N}_{2220}\right]\left[\mathrm{HSO}_{4}\right]$ containing $20 \% \mathrm{wt}$

for the $8 \mathrm{~h}$ pulp, and further to $257 / 1358$ for the $24 \mathrm{~h}$ pulp. In comparison, Hummel et al. found average DPs of 316/1658 (birch ECF Kraft pulp), 407/1662 (birch prehydrolysis Kraft pulp) and 493/3886 (eucalyptus prehydrolysis Kraft pulp) (Hummel et al. 2018). This suggests that the number average DPs measured for the Miscanthus ionoSolv pulps were lower than commercial dissolving grade pulps, while the weight average DPs could be competitive in terms of fibre length. It remains to be seen whether properties of ionosolv pulps after bleaching are suitable for dissolving pulp applications, and also how ionic liquid recycling affects the cellulose properties.

A DP of 100-200 is the DP typically found for elementary cellulose crystallites, which can be isolated with controlled acid hydrolysis, and is called level-off degree of polymerisation (LODP). The LODP is similar for most plant derived celluloses (Palme et al. 2016). We were unable to find a literature value for the LODP of Miscanthus cellulose, but we note that the DPs observed for ionoSolv pulps in this study were higher than LODPs reported for wood and cotton cellulose (Palme et al. 2016). Reducing the cellulose molar weight to a DP close to its LODP has been shown to be connected with a decrease in the polydispersity index (PDI), which we also observed here. When virtually all of the hemicellulose has been removed and a DP close to the natural LODP is

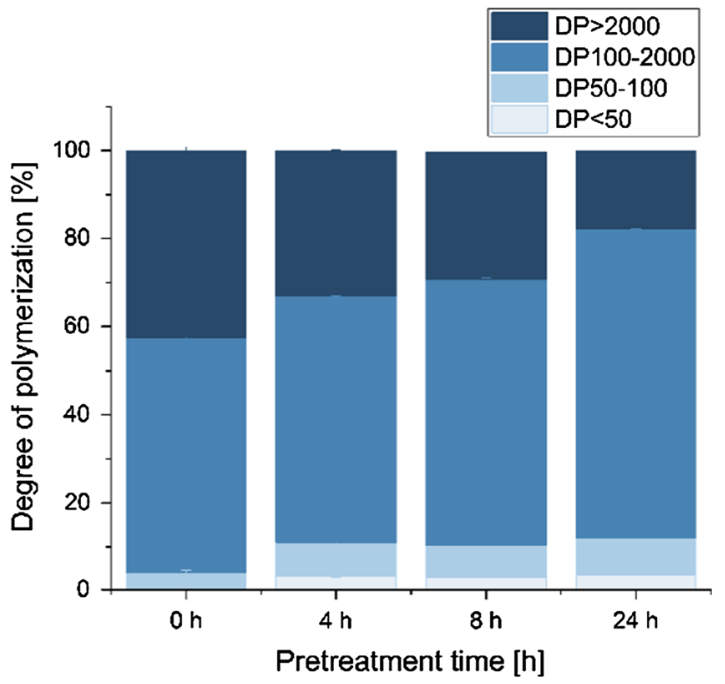

water at $120{ }^{\circ} \mathrm{C}$ (left). The abundance of cellulose polymers with a degree of polymerization below $50(<$ DP50), between 50-100 (DP50-100), between 100-2000 (DP100-2000), and above 2000 (> DP2000) are also shown (right)

reached, the polysaccharide PDI measured by SEC can be as low as 2.5 (Palme et al. 2016). Average DPs over 250 and PDIs above 3 observed for the ionoSolv pulps suggest that the LOPD was not reached even after prolonged ionoSolv fractionation. However, it may be possible that ionoSolv extraction can generate LODP sized cellulose crystals if further optimisation is pursued, with the potential of producing a bleachable pulp consisting of defined microcrystalline cellulose or even nanocellulose directly from lignocellulosic biomass.

Although we have evidence that the DP of cellulose is lowered during ionoSolv fractionation, we do not expect the observed reduction to contribute significantly to the enhanced enzymatic saccharification yields, given that the crystallinity of ionoSolv cellulose is high. It has been shown that cellulases peel off external cellulose chains one by one when they are part of crystalline fibrils, and hence shorter chains do not significantly increase speed of hydrolysis (Zhang et al. 2006).

\section{Conclusions}

This extensive characterisation of ionoSolv cellulose pulp derived from Miscanthus has provided several insights. Importantly, we have shown that cellulose 
pulps produced with low-cost hydrogen sulfate ionic liquids have a high degree of crystallinity. This confirms that ionic liquids such as $\left[\mathrm{N}_{2220}\right]\left[\mathrm{HSO}_{4}\right]$ do not change the lattice structure of cellulose. This contrasts with the action of cellulose dissolving ionic liquids, which are well-known to reduce cellulose crystallinity, accompanied by limited production of cellulose II.

We found that the removal of lignin and hemicellulose observed during compositional analysis of ionoSolv treated pulps enhanced the measured crystallinity index compared to untreated biomass. We also showed that the removal of the matrix polymers lignin and hemicelluloses resulted in the coalescence of the exposed cellulose fibrils, which is commonly observed in dried cellulose-rich pulps.

GPC analysis revealed that fractionation with the acidic ionic liquid water solution decreased the polysaccharide molar weight in the pulp and, associated with this, the degree of polymerisation. This was due to hemicellulose extraction but also due to depolymerisation of longer cellulose chains (DP > 2000). We propose that the hydrolysis reactions in cellulose were limited to the amorphous domains of the cellulose fibrils, leaving behind an increasing number of elementary cellulose fibril crystallites. Generation of the elementary crystallites was not complete under the conditions applied in this study, even when using extended pretreatment times, but the LDOP may be reached if higher severity is applied, opening up the possibility to produce nanocellulose in one step, if the pulp is found to be bleachable.

We further demonstrated that ionoSolv pretreatment impacted the surface morphology, revealing that there was a reduction in the particle size and an increase in the surface area by nearly an order of magnitude upon ionoSolv fractionation. We assigned the reduction in particle size to particle fragmentation and peeling off as observed in electron micrographs. The particle fragmentation was likely caused by the extraction of the hemicellulose lignin polymer matrix that encapsulates the cellulose fibres.

We were also able to shed more light on what happens to the pulp in the overtreatment regime, which is observed when ionoSolv fractionation is continued beyond the optimum deconstruction point. We showed that the observed increase in Klason lignin content in overtreated pulp was accompanied by a modest increase in particle size and a decrease in surface area, which is consistent with deposition of pseudolignin on the surface of pulp particles. We could confirm presence of pseudolignin with FT-IR spectroscopy, although detailed structural analysis remains to be carried out.

The study confirms that ionoSolv pretreatment enhances high enzymatic saccharification yields due to the known effect of lignin and hemicellulose removal. This and the accompanying surface area enhancement exposes cellulose fibrils that were not accessible to enzymes in untreated biomass. Since cellulose crystallinity remains high, we propose that the increased amount of cellulose fibril surface is the main cause of enhanced enzymatic hydrolysis yields, with reduced unproductive binding of enzymes due to extensive lignin removal as a secondary effect.

In summary, we demonstrate for the first time that ionoSolv pulps have potential to be further refined for material applications, as we found that the cellulose in the delignified pulp was highly crystalline, making it potentially suitable source of micro- and nanocellulose but also dissolving pulp. This could open up applications in addition to producing purified glucose for biorefining via enzymatic saccharification.

Acknowledgements The authors would like to acknowledge the Engineering and Physical Sciences Research Council (EP/ S000771/1) for funding.

Open Access This article is licensed under a Creative Commons Attribution 4.0 International License, which permits use, sharing, adaptation, distribution and reproduction in any medium or format, as long as you give appropriate credit to the original author(s) and the source, provide a link to the Creative Commons licence, and indicate if changes were made. The images or other third party material in this article are included in the article's Creative Commons licence, unless indicated otherwise in a credit line to the material. If material is not included in the article's Creative Commons licence and your intended use is not permitted by statutory regulation or exceeds the permitted use, you will need to obtain permission directly from the copyright holder. To view a copy of this licence, visit http://creativecommons.org/licenses/by/4.0/.

\section{References}

Alvira P, Tomás-Pejó E, Ballesteros M, Negro MJ (2010) Pretreatment technologies for an efficient bioethanol production process based on enzymatic hydrolysis: a review. Bioresour Technol 101:4851-4861. https://doi.org/10. 1016/j.biortech.2009.11.093 
Baral NR, Shah A (2016) Techno-economic analysis of cellulose dissolving ionic liquid pretreatment of lignocellulosic biomass for fermentable sugars production. Biofuels Bioprod Biorefining 10:70-88. https://doi.org/10.1002/bbb. 1622

Berg P, Lingqvist O (2017) Pulp, paper, and packaging in the next decade: transformational change. McKinsey \& Company, New York

Borrega M, Concha-Carrasco S, Pranovich A, Sixta H (2017) Hot water treatment of hardwood kraft pulp produces highpurity cellulose and polymeric xylan. Cellulose 24:5133-5145. https://doi.org/10.1007/s10570-017-1462$\mathrm{Z}$

Brandt A, Chen L, van Dongen BE, Welton T, Hallett JP (2015) Structural changes in lignins isolated using an acidic ionic liquid water mixture. Green Chem 17:5019-5034. https:// doi.org/10.1039/C5GC01314C

Brandt A, Grasvik J, Hallett JP, Welton T (2013) Deconstruction of lignocellulosic biomass with ionic liquids. Green Chem 15:550-583. https://doi.org/10.1039/C2GC36364J

Brandt A, Hallett JP, Leak DJ, Murphy RJ, Welton T (2010) The effect of the ionic liquid anion in the pretreatment of pine wood chips. Green Chem 12:672-679. https://doi.org/10. 1039/b918787a

Brandt A, Ray MJ, To TQ, Leak DJ, Murphy RJ, Welton T (2011) Ionic liquid pretreatment of lignocellulosic biomass with ionic liquid-water mixtures. Green Chem 13:2489-2499. https://doi.org/10.1039/c1gc15374a

Brandt-Talbot A, Gschwend FJV, Fennell PS, Lammens TM, Tan B, Weale J, Hallett JP (2017) An economically viable ionic liquid for the fractionation of lignocellulosic biomass. Green Chem 19:3078-3102. https://doi.org/10.1039/ C7GC00705A

Chambon CL, Chen M, Fennell PS, Hallett JP (2019) Efficient fractionation of lignin- and ash-rich agricultural residues following treatment with a low-cost protic ionic liquid. Front Chem. https://doi.org/10.3389/fchem.2019.00246

Chambon CL, Mkhize TY, Reddy P, Brandt-Talbot A, Deenadayalu N, Fennell PS, Hallett JP (2018) Pretreatment of South African sugarcane bagasse using a low-cost protic ionic liquid: a comparison of whole, depithed, fibrous and pith bagasse fractions. Biotechnology for Biofuels 11:247. https://doi.org/10.1186/s13068-018-1247-0

Chen H (2014) Biotechnology of Lignocellulose. Springer, Amsterdam. https://doi.org/10.1007/978-94-007-6898-7

Chen Y, Wang Y, Wan J, Ma Y (2010) Crystal and pore structure of wheat straw cellulose fiber during recycling. Cellulose 17:329-338. https://doi.org/10.1007/s10570009-9368-Z

Cheng G et al (2011) Transition of cellulose crystalline structure and surface morphology of biomass as a function of ionic liquid pretreatment and its relation to enzymatic hydrolysis. Biomacromolecules 12:933-941. https://doi.org/10. $1021 / \mathrm{bm} 101240 \mathrm{z}$

Clark JH (2007) Green chemistry for the second generation biorefinery-sustainable chemical manufacturing based on biomass. J Chem Technol Biotechnol 82:603-609. https:// doi.org/10.1002/jctb. 1710

Clough MT, Geyer K, Hunt PA, Mertes J, Welton T (2013) Thermal decomposition of carboxylate ionic liquids: trends and mechanisms. Phys Chem Chem Phys 15:20480-20495. https://doi.org/10.1039/C3CP53648C

da Costa SL, Chundawat SPS, Balan V, Dale BE (2009) 'Cradleto-grave' assessment of existing lignocellulose pretreatment technologies. Curr Opin Biotechnol 20:339-347. https://doi.org/10.1016/j.copbio.2009.05.003

Dadi AP, Varanasi S, Schall CA (2006) Enhancement of cellulose saccharification kinetics using an ionic liquid pretreatment step. Biotechnol Bioeng 95:904-910. https://doi. org/10.1002/bit.21047

Davison BH, Parks J, Davis MF, Donohoe BS (2013) Plant cell walls: basics of structure, chemistry, accessibility and the influence on conversion In aqueous pretreatment of plant biomass for biological and chemical conversion to fuels and chemicals. In: Wyman CE (ed) Aqueous pretreatment of plant biomass for biological and chemical conversion to fuels and chemicals. Wiley, Hoboken, pp. 23-38. https:// doi.org/10.1002/9780470975831.ch3

Doherty TV, Mora-Pale M, Foley SE, Linhardt RJ, Dordick JS (2010) Ionic liquid solvent properties as predictors of lignocellulose pretreatment efficacy. Green Chem 12:1967-1975. https://doi.org/10.1039/C0GC00206B

Edgar KJ, Buchanan CM, Debenham JS, Rundquist PA, Seiler BD, Shelton MC, Tindall D (2001) Advances in cellulose ester performance and application. Prog Polym Sci 26:1605-1688. 6700(01)00027-2

Ek M, Gellerstedt G, Henriksson G (2009) Volume 2 Pulping chemistry and technology. De Gruyter, Berlin, Boston. https://doi.org/10.1515/9783110213423

FAO (2017) Yearbook of Forest Products 2016. Food and Agriculture Organisation of the United Nations, Rome

French AD, Santiago Cintrón M (2013) Cellulose polymorphy, crystallite size, and the Segal Crystallinity Index. Cellulose 20:583-588. https://doi.org/10.1007/s10570-012-9833-y

George A et al (2015) Design of low-cost ionic liquids for lignocellulosic biomass pretreatment. Green Chem 17:1728-1734. https://doi.org/10.1039/C4GC01208A

De Gregorio GF, Weber CC, Gräsvik J, Welton T, Brandt A, Hallett JP (2016) Mechanistic insights into lignin depolymerisation in acidic ionic liquids. Green Chem 18:5456-5465. https://doi.org/10.1039/C6GC01295G

Gschwend FJV, Brandt A, Chambon CL, Tu W-C, Weigand L, Hallett JP (2016) Pretreatment of lignocellulosic biomass with low-cost ionic liquids. JoVE. https://doi.org/10.3791/ 54246

Gschwend FJV, Chambon CL, Biedka M, Brandt-Talbot A, Fennell PS, Hallett JP (2019) Quantitative glucose release from softwood after pretreatment with low-cost ionic liquids. Green Chem 21:692-703. https://doi.org/10.1039/ C8GC02155D

Gschwend FJV, Malaret F, Shinde S, Brandt-Talbot A, Hallett JP (2018) Rapid pretreatment of Miscanthus using the lowcost ionic liquid triethylammonium hydrogen sulfate at elevated temperatures. Green Chem 20:3486-3498. https:// doi.org/10.1039/C8GC00837J

Habibi Y, Lucia LA, Rojas OJ (2010) Cellulose nanocrystals: chemistry, self-assembly, and applications. Chem Rev 110:3479-3500. https://doi.org/10.1021/cr900339w 
Hallett JP, Welton T (2011) Room-temperature ionic liquids: solvents for synthesis and catalysis 2. Chem Rev 111:3508-3576. https://doi.org/10.1021/cr1003248

Hargreaves NJ, Cooper SJ (2016) Nanographite synthesized from acidified sucrose microemulsions under ambient conditions. Cryst Growth Des 16:3133-3142. https://doi. org/10.1021/acs.cgd.5b01753

Horn RA (1978) Morphology of pulp fibre from hardwoods and influence on paper strength. Research Paper FPL 312. Forest Products Laboratory, U.S. Department of Agriculture, Madison, Winsconsin

Hu F, Jung S, Ragauskas A (2012) Pseudo-lignin formation and its impact on enzymatic hydrolysis. Bioresour Technol 117:7-12. https://doi.org/10.1016/j.biortech.2012.04.037

Hummel M et al (2018) High-performance lignocellulosic fibers spun from ionic liquid solution. In: Rosenau T, Potthast A, Hell J (eds) Cellulose science and technology. Wiley, Amsterdam, pp. 341-370. https://doi.org/10.1002/ 9781119217619.ch14

Ji Z, Zhang X, Ling Z, Sun R-C, Xu F (2016) Tissue specific response of Miscanthus $\times$ giganteus to dilute acid pretreatment for enhancing cellulose digestibility. Carbohydrate Polym 154:247-256. https://doi.org/10.1016/j.carbpol. 2016.06.086

Karim L (2017) Probing cellulase stability in low cost mineral acid ionic liquids. $\mathrm{PhD}$ Thesis, Imperial College London

Kontturi E et al (2016) Degradation and crystallization of cellulose in hydrogen chloride vapor for high-yield isolation of cellulose. Nanocryst Angew Chem Int Ed 55:14455-14458. https://doi.org/10.1002/anie.201606626

Kumar A, Negi YS, Choudhary V, Bhardwaj NK (2014) Characterization of cellulose nanocrystals produced by acid-hydrolysis from sugarcane bagasse as agro-waste. J Mater Phys Chem 2:1-8. https://doi.org/10.12691/jmpc2-1-1

Kuzmina O (2016) Chapter 5: methods of IL recovery and destruction. In: Kuzmina O, Hallett JP (eds) Application, purification, and recovery of ionic liquids. Elsevier, Amsterdam, pp. 205-248. https://doi.org/10.1016/B978-0-44463713-0.00005-5

Li C et al (2010) Comparison of dilute acid and ionic liquid pretreatment of switchgrass: Biomass recalcitrance, delignification and enzymatic saccharification. Bioresour Technol 101:4900-4906. https://doi.org/10.1016/j. biortech.2009.10.066

Li C et al (2011) Influence of physico-chemical changes on enzymatic digestibility of ionic liquid and AFEX pretreated corn stover. Bioresour Technol 102:6928-6936. https://doi.org/10.1016/j.biortech.2011.04.005

Li T-Q, Henriksson U, Odberg L (1993) Determination of pore sizes in wood cellulose fibers by $2 \mathrm{H}$ and $\mathrm{H}$. NMR. https:// doi.org/10.3183/npprj-1993-08-03-p326-330

Liu Y et al (2014) Study on biodegradation process of lignin by FTIR and DSC. Environ Sci Pollution Res 21:14004-14013. https://doi.org/10.1007/s11356-014$3342-5$

Mao J, Heck B, Reiter G, Laborie M-P (2015) Cellulose nanocrystals' production in near theoretical yields by 1-butyl-3-methylimidazolium hydrogen sulfate ([Bmim]HSO4)-mediated hydrolysis. Carbohydrate Polym
117:443-451. https://doi.org/10.1016/j.carbpol.2014.10. 001

Osong SH, Norgren S, Engstrand P (2016) Processing of woodbased microfibrillated cellulose and nanofibrillated cellulose, and applications relating to papermaking: a review. Cellulose 23:93-123. https://doi.org/10.1007/s10570-0150798-5

Palme A, Theliander H, Brelid H (2016) Acid hydrolysis of cellulosic fibres: comparison of bleached kraft pulp, dissolving pulps and cotton textile cellulose. Carbohydrate Polym 136:1281-1287. https://doi.org/10.1016/j.carbpol. 2015.10.015

Plechkova NV, Seddon KR (2008) Applications of ionic liquids in the chemical industry. Chem Soc Rev 37:123-150. https://doi.org/10.1039/B006677J

Resch MJ, Baker JO, Decker SR (2015) Low solids enzymatic saccharification of lignocellulosic biomass. National Renewable Energy Laboratory, US Department of Energy

Scherrer P (1912) Bestimmung der inneren Struktur und der Größe von Kolloidteilchen mittels Röntgenstrahlen. In: Zsigmondy R (ed) Kolloidchemie Ein Lehrbuch. Springer, Berlin, pp. 387-409. https://doi.org/10.1007/978-3-66233915-2_7

Segal L, Creely JJ, Martin AE, Conrad CM (1959) an empirical method for estimating the degree of crystallinity of native cellulose using the x-ray diffractometer. Text Res J 29:786-794. 004051755902901003

https://doi.org/10.1177/

Seidel C-M, Pielhop T, Studer MH, Rudolf von Rohr P (2017) The influence of the explosive decompression in steamexplosion pretreatment on the enzymatic digestibility of different biomasses. Faraday Discuss 202:269-280. https:// doi.org/10.1039/C7FD00066A

Shatkin JA, Wegner TH, Bilek TEM, Cowie J (2014) Market projections of cellulose nanomaterial-enabled productsPart 1: applications. Tappi J 13:9-16. https://doi.org/10. 32964/tj13.5.9

Shinde SD, Meng X, Kumar R, Ragauskas AJ (2018) Recent advances in understanding the pseudo-lignin formation in a lignocellulosic biorefinery. Green Chem 20:2192-2205. https://doi.org/10.1039/C8GC00353J

Sjöholm E, Gustafsson K, Berthold F, Colmsjö A (2000) Influence of the carbohydrate composition on the molecular weight distribution of kraft pulps. Carbohydrate Polym 41:1-7. https://doi.org/10.1016/S0144-8617(99)00066-1

Sluiter A et al (2008) Determination of total solids in biomass and total dissolved solids in liquid process samples. National Renewable Energy Laboratory, US Department of Energy

Sluiter A, Hames B, Ruiz R, Scarlata C, Sluiter J, Templeton D, Crocker D (2012) Determination of structural carbohydrates and lignin in biomass. National Renewable Energy Laboratory, US Department of Energy

Socha AM, Plummer SP, Stavila V, Simmons BA, Singh S (2013) Comparison of sugar content for ionic liquid pretreated Douglas-fir woodchips and forestry residues. Biotechnol Biofuels 6:61. https://doi.org/10.1186/17546834-6-61

Sun Q et al (2014) Effect of lignin content on changes occurring in poplar cellulose ultrastructure during dilute acid 
pretreatment. Biotechnol Biofuels 7:150. https://doi.org/ 10.1186/s13068-014-0150-6

Sun J et al (2017) One-pot integrated biofuel production using low-cost biocompatible protic ionic liquids. Green Chem 19:3152-3163. https://doi.org/10.1039/C7GC01179B

Tsaneva VN, Kwapinski W, Teng X, Glowacki BA (2014) Assessment of the structural evolution of carbons from microwave plasma natural gas reforming and biomass pyrolysis using Raman spectroscopy. Carbon 80:617-628. https://doi.org/10.1016/j.carbon.2014.09.005

Verdia P, Brandt A, Hallett JP, Ray MJ, Welton T (2014) Fractionation of lignocellulosic biomass with the ionic liquid 1-butylimidazolium hydrogen sulphate. Green Chem 16:1617-1627. https://doi.org/10.1039/ C3GC41742E

Weigand L, Mostame S, Brandt-Talbot A, Welton T, Hallett JP (2017) Effect of pretreatment severity on the cellulose and lignin isolated from Salix using ionoSolv pretreatment. Faraday Discuss 202:331-349. https://doi.org/10.1039/ C7FD00059F

Wise LE (1946) Chlorite holocellulose, its fractionation and bearing on summative wood analysis and studies on the hemicelluloses. Paper Trade J 122:35-43
Xu F, Yu J, Tesso T, Dowell F, Wang D (2013) Qualitative and quantitative analysis of lignocellulosic biomass using infrared techniques: a mini-review. Appl Energy 104:801-809. https://doi.org/10.1016/j.apenergy.2012.12. 019

Zhang YHP, Cui J, Lynd LR, Kuang LR (2006) A transition from cellulose swelling to cellulose dissolution by o-phosphoric acid: evidence from enzymatic hydrolysis and supramolecular structure. Biomacromolecules 7:644-648. https://doi.org/10.1021/bm050799c

Zhang M, Qi W, Liu R, Su R, Wu S, He Z (2010) Fractionating lignocellulose by formic acid: characterization of major components. Biomass Bioenergy 34:525-532. https://doi. org/10.1016/j.biombioe.2009.12.018

Zhao X, Cheng K, Liu D (2009) Organosolv pretreatment of lignocellulosic biomass for enzymatic hydrolysis. Appl Microbiol Biotechnol 82:815-827. https://doi.org/10. 1007/s00253-009-1883-1

Publisher's Note Springer Nature remains neutral with regard to jurisdictional claims in published maps and institutional affiliations. 